\title{
Cisto odontogênico glandular em maxila: relato de caso
}

\section{Glandular odontogenic cyst in maxilla: case report}

\author{
Emanuene Galdino Pires ${ }^{1}$ \\ Paulo Rogério Ferreti Bonan² \\ Tony Santos Peixoto 3 \\ Bárbara Vanessa de Brito Monteiro ${ }^{4}$ \\ Cassiano Francisco Weege Nonaka ${ }^{5}$ \\ Pollianna Muniz Alves ${ }^{5}$
}

\begin{abstract}
RESUMO
Introdução: O cisto odontogênico glandular (COG) é uma lesão rara, correspondendo a 0,3\% de todos os cistos odontogênicos. O COG é localmente agressivo, acomete com maior frequência a região anterior de mandíbula e compartilha características microscópicas com outras lesões císticas e neoplásicas.

Objetivo: Relatar um caso de COG em maxila, abordando suas características clinicopatológicas, diagnóstico diferencial e terapêutica.

Relato de caso: Paciente do gênero feminino, 61 anos de idade, apresentou-se para avaliação de uma tumefação assintomática localizada em maxila, na área dos dentes 11 ao 24. Exames imaginológicos evidenciaram lesão hipodensa, multilocular e expansiva que determinava rompimento das corticais ósseas vestibular e palatina da maxila. Sob hipótese diagnóstica de ameloblastoma, foi realizada biópsia incisional. O exame histopatológico revelou múltiplas cavidades císticas revestidas por epitélio não ceratinizado de espessura variável, com células superficiais de morfologia que variavam de escamosa a colunar, intercaladas por células mucosas. No revestimento epitelial também foram constatados espessamentos em forma de placa, projeções papilares e espaços microcísticos. Com base nos achados microscópicos, foi estabelecido o diagnóstico conclusivo de COG. O tratamento realizado consistiu em clivagem óssea perilesional, seguida de curetagem e osteoplastia. Doze meses após a remoção cirúrgica da lesão, não foram constatados sinais clínicos ou radiográficos de recidiva.

Conclusão: O COG é uma lesão localmente agressiva, cujo diagnóstico diferencial inclui cistos e neoplasias dos ossos gnáticos com comportamentos biológicos diversos. Levando-se em consideração a possibilidade de recorrência tardia dos COGs, o acompanhamento dos pacientes a longo prazo é de grande valia.

Palavras-chave: Cistos odontogênicos. Diagnóstico diferencial. Patologia. Patologia Bucal. Cirurgia bucal.
\end{abstract}

\begin{abstract}
Introduction: Glandular odontogenic cyst (GOC) is a rare lesion, corresponding to $0.3 \%$ of all odontogenic cysts. COG is locally aggressive, most often affects the anterior region of the mandible and shares microscopic features with other cystic and neoplastic lesions.

Objective: To report a case of GOC in maxilla, addressing its clinicopathological features, differential diagnosis and therapeutics.

Case report: A 61-year-old female patient presented for evaluation of an asymptomatic swelling in the maxilla, in the area of teeth 11 to 24 . Imaging examinations revealed a hypodense, multilocular, expansive lesion with rupture of the maxillary vestibular and palatal bone cortices. Under the diagnostic hypothesis of ameloblastoma, an incisional biopsy was performed. Histopathological examination revealed multiple cystic cavities lined with non-keratinized epithelium of varying thickness, with superficial cells showing squamous to columnar morphology, interspersed with mucous cells. Plaque-like thickenings, papillary projections and microcystic spaces could also be observed in the epithelial lining. Based on microscopic features,
\end{abstract}

\footnotetext{
Doutoranda do Programa de Pós-Graduação em Odontologia, Universidade Estadual da Paraíba, Campina Grande, PB. Professor Doutor do Programa de Pós-Graduação em Odontologia, Universidade Federal da Paraíba, João Pessoa, PB. Doutorando do Programa de Pós-Graduação em Clínica Odontológica, Universidade Estadual de Campinas, Campinas, SP. Professora Doutora do Centro de Saúde e Tecnologia Rural, Curso de Odontologia, Universidade Federal de Campina Grande, Patos, PB. Professor Doutor do Programa de Pós-Graduação em Odontologia, Universidade Estadual da Paraíba, Campina Grande, PB.
} 
the conclusive diagnosis was GOC. The treatment consisted of perilesional bone cleavage, followed by curettage and osteoplasty. Twelve months after surgical excision of the lesion, no clinical or radiographic signs of recurrence were observed.

Conclusion: GOC is a locally aggressive lesion, whose differential diagnosis includes cysts and neoplasms of the gnathic bones with diverse biological behaviors. Taking into account the possibility of late recurrence of GOCs, long-term follow-up of patients is of great value.

Keywords: Odontogenic cysts. Differential diagnosis. Pathology. Oral Pathology. Oral surgery.

\section{INTRODUÇÃO}

O cisto odontogênico glandular (COG) foi relatado pela primeira vez por Padayachee e Van Wyk, ${ }^{1}$ em 1987, sob a designação de "cisto sialo-odontogênico", devido à sua semelhança histopatológica com tumores de glândulas salivares produtores de muco. Em 1988, Gardner et al. ${ }^{2}$ descreveram oito casos com características histopatológicas semelhantes às reportadas por Padayachee e Van $W_{y k}{ }^{1} e$, por considerarem que essa lesão não possuía origem glandular salivar, sugeriram o termo COG. Desde a segunda classificação dos cistos odontogênicos da Organização Mundial da Saúde, publicada em 1992, essa lesão tem sido definida como um cisto odontogênico de desenvolvimento. ${ }^{3,4}$

O COG representa aproximadamente $0,3 \%$ de todos os cistos odontogênicos ${ }^{5}$ e tem uma maior prevalência entre a quarta e a sexta décadas de vida, sendo mais frequente em indivíduos do gênero masculino. ${ }^{6,7}$ É uma lesão localmente agressiva, ${ }^{8}$ usualmente extensa, que afeta a região anterior de mandíbula, seguida pela região anterior de maxila, atravessando a linha média. ${ }^{6,7}$ Radiograficamente, apresentase como uma área radiolúcida bem definida, uni ou multilocular. ${ }^{6,8}$ Ruptura de corticais ósseas, reabsorção radicular e impactação dentária também têm sido relatadas em alguns casos. ${ }^{8}$

Microscopicamente, o COG é caracterizado por um revestimento epitelial não ceratinizado, de espessura variável, com células superficiais que variam de escamosas a colunares. ${ }^{7,9}$ Nesse componente epitelial, podem ser identificadas projeções papilares, espessamentos nodulares, estruturas semelhantes a ductos e espaços microcísticos. Destacam-se, ainda, quantidades variáveis de células mucosas e células claras. ${ }^{8,10} \mathrm{~A}$ cáp sula fibrosa, usualmente, se apresenta livre de inflamação. ${ }^{9}$

O tratamento para $O \quad$ COG varia desde abordagens conservadoras, como enucleação e curetagem, até ressecções segmentares. ${ }^{7,8,10}$ Estudos mostram que, devido ao seu comportamento agressivo, existe grande propensão ao desenvolvimento de recorrências, observadas em $17 \%$ a $50 \%$ dos casos. $6,8,11,12$

Este trabalho objetivou relatar um caso de COG em maxila, abordando suas características clinicopatológicas, diagnóstico diferencial e terapêutica.

\section{Relato do CAso}

Paciente do gênero feminino, 61 anos de idade, melanoderma, foi encaminhada ao ambulatório do Hospital da Fundação Assistencial da Paraíba - Campina Grande - Paraíba - Brasil para avaliação de lesão na região anterior da maxila, associada à mobilidade dos dentes envolvidos na lesão. Durante a anamnese, constatou-se que a paciente apresentava um bom estado de saúde geral. O exame físico extraoral revelou um aumento de volume que ocasionava elevação da asa do nariz no lado esquerdo, com consequente assimetria no terço médio da face. Não foram observados linfonodos cervicais alterados à palpação. Ao exame físico intraoral, verificou-se tumefação assintomática na região anterior de maxila, na área correspondente aos dentes 11 ao 24, com aproximadamente 3,6 $\mathrm{cm}$ de diâmetro. A lesão, de crescimento lento, 
se mostrava recoberta por mucosa íntegra que exibia áreas discretamente azuladas. Tais áreas de discromia apresentavam, à palpação, consistência flutuante. Para a participação no estudo, a paciente assinou o Termo de Consentimento Livre e Esclarecido.

O exame radiográfico panorâmico revelou uma imagem radiolúcida multilocular, de bordos relativamente regulares, localizada na maxila e se estendendo da mesial do dente 11 até a distal do dente 24 (Figura 1A). Por sua vez, o exame de tomografia computadorizada de feixe cônico evidenciou uma imagem hipodensa e expansiva que determinava rompimento da parede lateral da fossa nasal esquerda (Figura 1B), bem como, das corticais ósseas vestibular e palatina da maxila (Figura 1C e 1D).

Ancorado nos achados clínicos e radiográficos foi estabelecida a hipótese diagnóstica de ameloblastoma. Após a realização de biópsia incisional, o material obtido foi fixado em formol a $10 \%$ e encaminhado para análise histopatológica. O exame microscópico revelou múltiplas cavidades císticas revestidas por epitélio não ceratinizado de espessura variável, com áreas focais de espessamentos em forma de
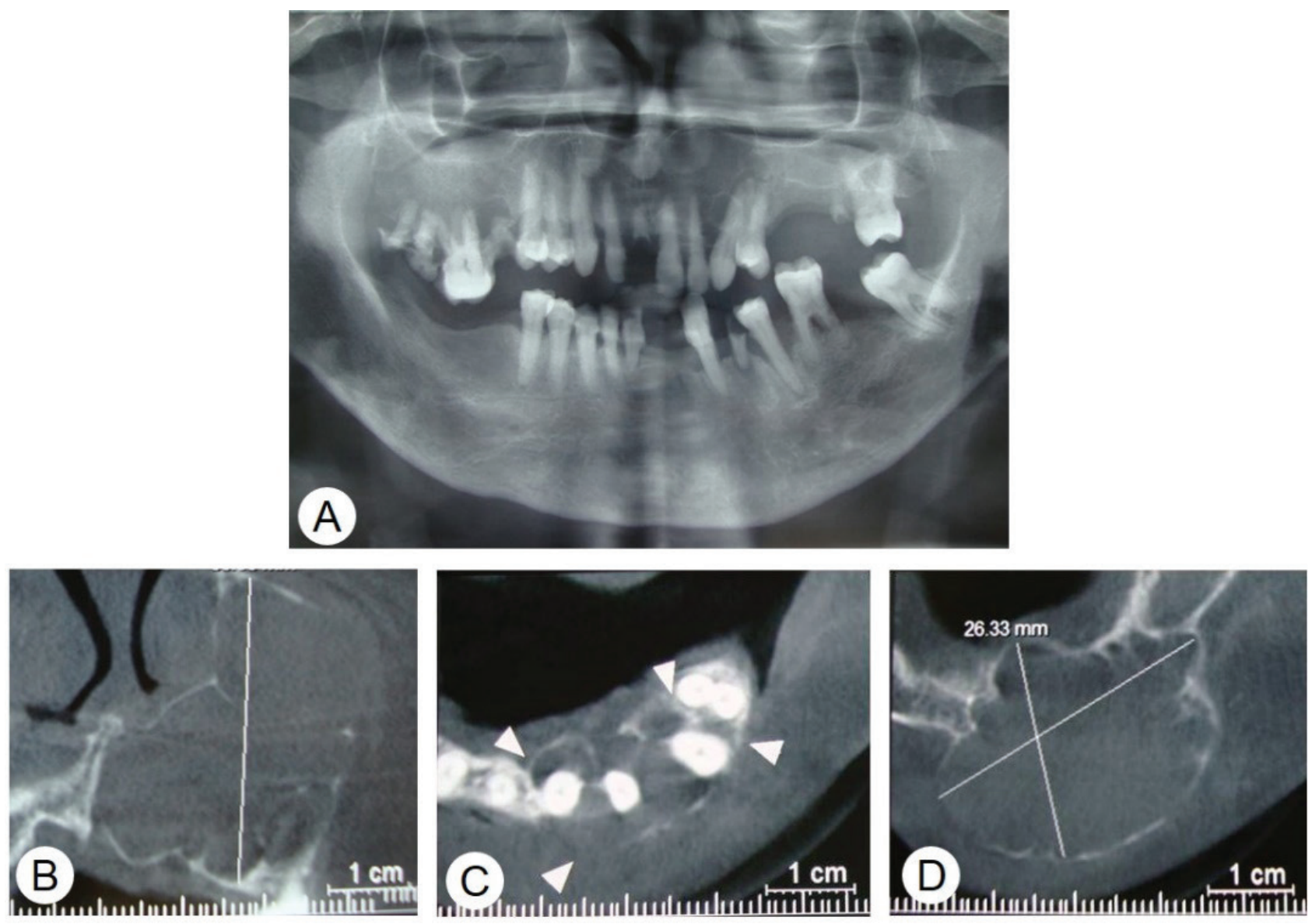

Figura 1 -A) Radiografia panorâmica demonstrando imagem radiolúcida multilocular, de bordos regulares, se estendendo da mesial do dente 11 até a distal do dente 24. B) Corte coronal da tomografia computadorizada evidenciando extensa lesão hipodensa e expansiva que determinava rompimento da parede lateral da fossa nasal esquerda. C) Corte axial da tomografia computadorizada evidenciando o aspecto multilocular da lesão e o rompimento parcial das corticais ósseas. D) Corte axial da tomografia computadorizada evidenciando expansão das corticais ósseas vestibular e palatina da maxila. 
placa e ocasionais projeções papilares (Figura $2 \mathrm{~A}$ ). A superfície epitelial apresentava células cuboidais, colunares ou escamosas que, por vezes, eram substituídas por células mucosas proeminentes (Figura 2B). Destacava-se, ainda, a presença de células claras em áreas da camada basal, além de espaços microcísticos revestidos por células cuboidais em regiões mais superficiais do revestimento epitelial (Figuras 2C e 2D). A cápsula fibrosa, de densidade variável, mostrava áreas de discreto infiltrado inflamatório mononuclear e eventuais focos de extravasamento hemorrágico (Figura 2B).
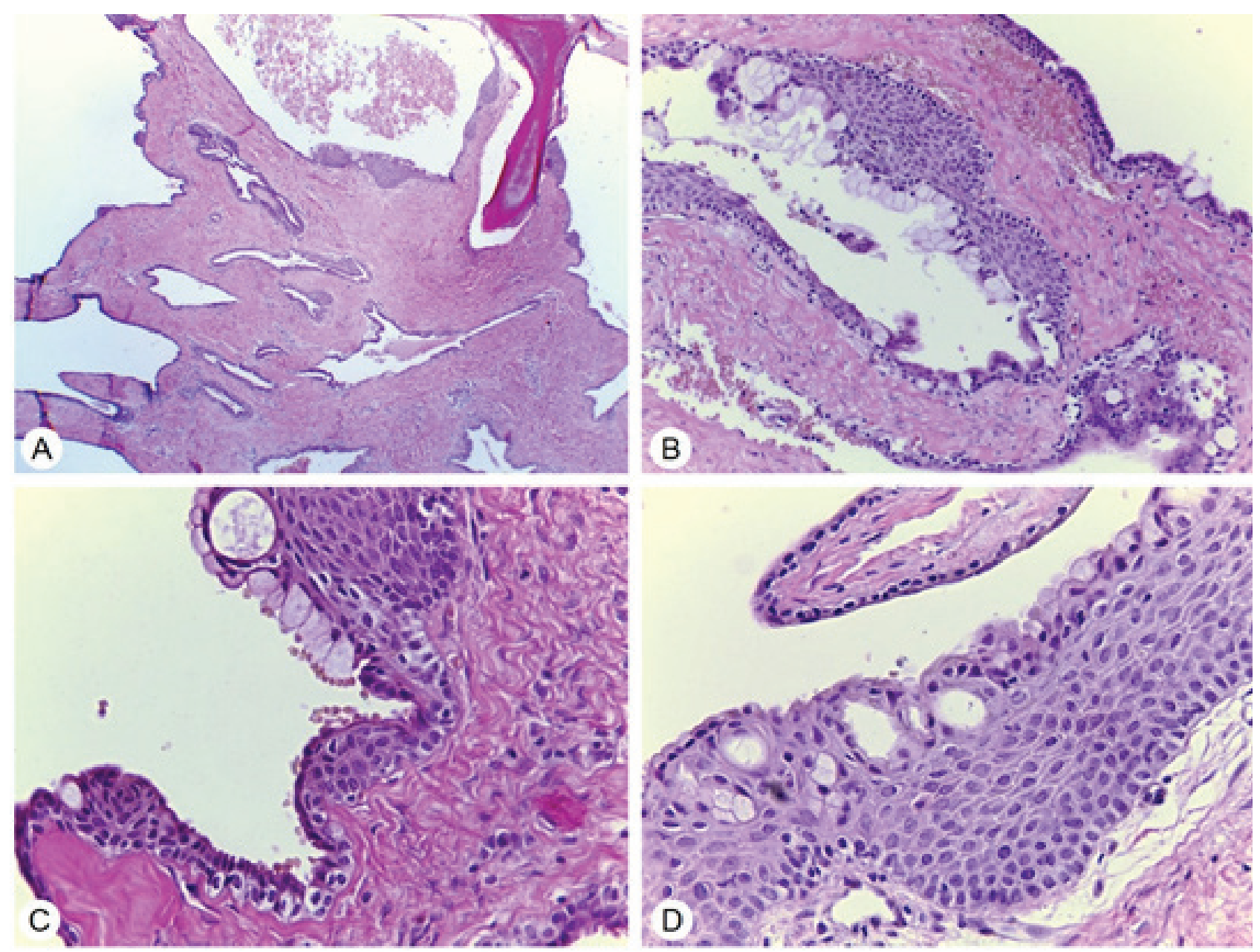

Figura 2 - A) Fotomicrografia evidenciando múltiplas cavidades císticas revestidas por epitélio de espessura variável (coloração em H.E. e aumento de 40x). B) Diversas células mucosas no revestimento epitelial e áreas de extravasamento hemorrágico e discreto infiltrado inflamatório na cápsula fibrosa (coloração em H.E. e aumento de 200x). C) Destaque para os espessamentos focais, a variabilidade das células superficiais e as células claras em camada basal (coloração em H.E. e aumento de 400x). D) Presença de espaços microcísticos revestidos por células cuboidais (coloração em H.E. e aumento de 400x). 
Com base nos achados microscópicos, foi estabelecido o diagnóstico conclusivo de COG. $\mathrm{O}$ tratamento realizado consistiu em clivagem óssea perilesional, seguida de curetagem e osteoplastia (Figura 3). Após 12 meses da remoção cirúrgica da lesão, foi verificada neoformação óssea local e ausência de sinais clínicos ou radiográficos de recidiva (Figura 4). A paciente permanece sob proservação periódica.

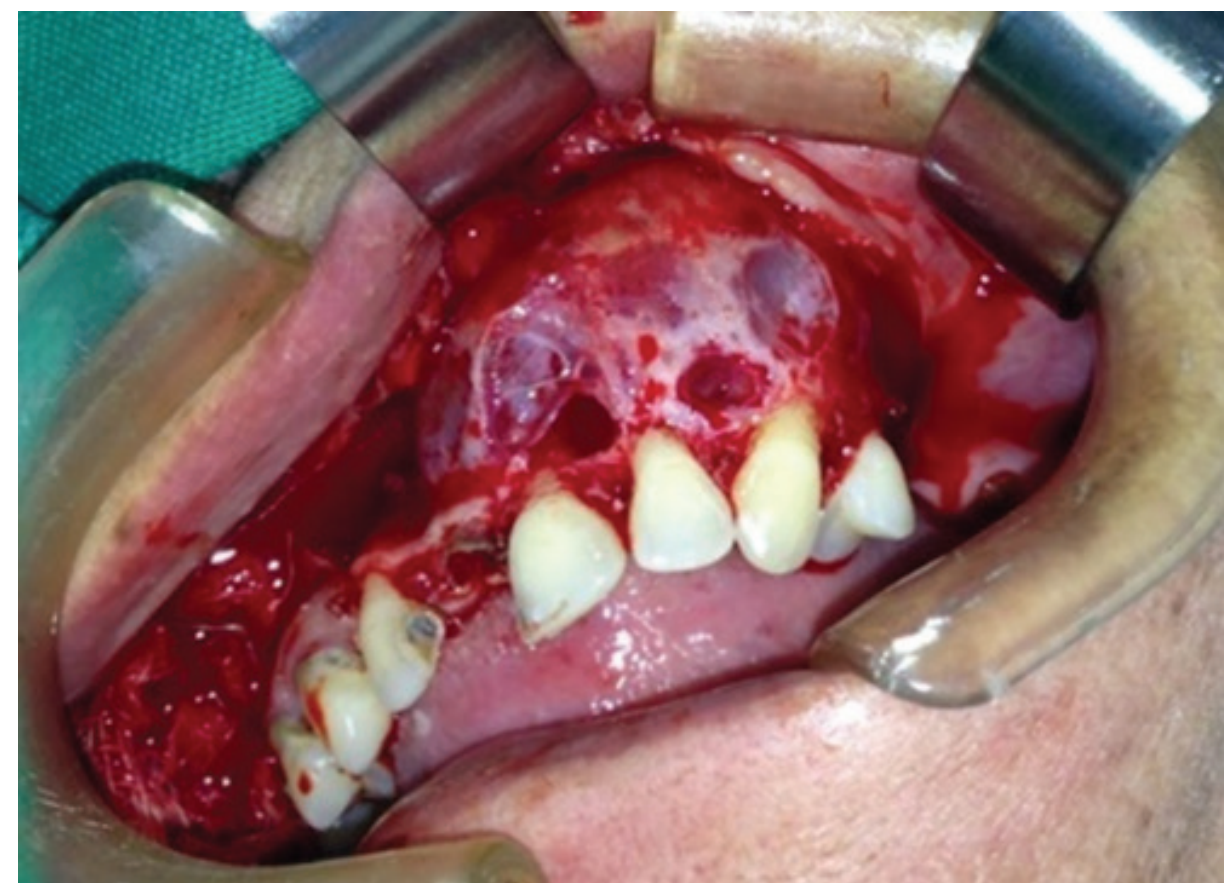

Figura 3 - Imagem transcirúrgica evidenciando expansão e perfurações na cortical óssea vestibular da maxila.

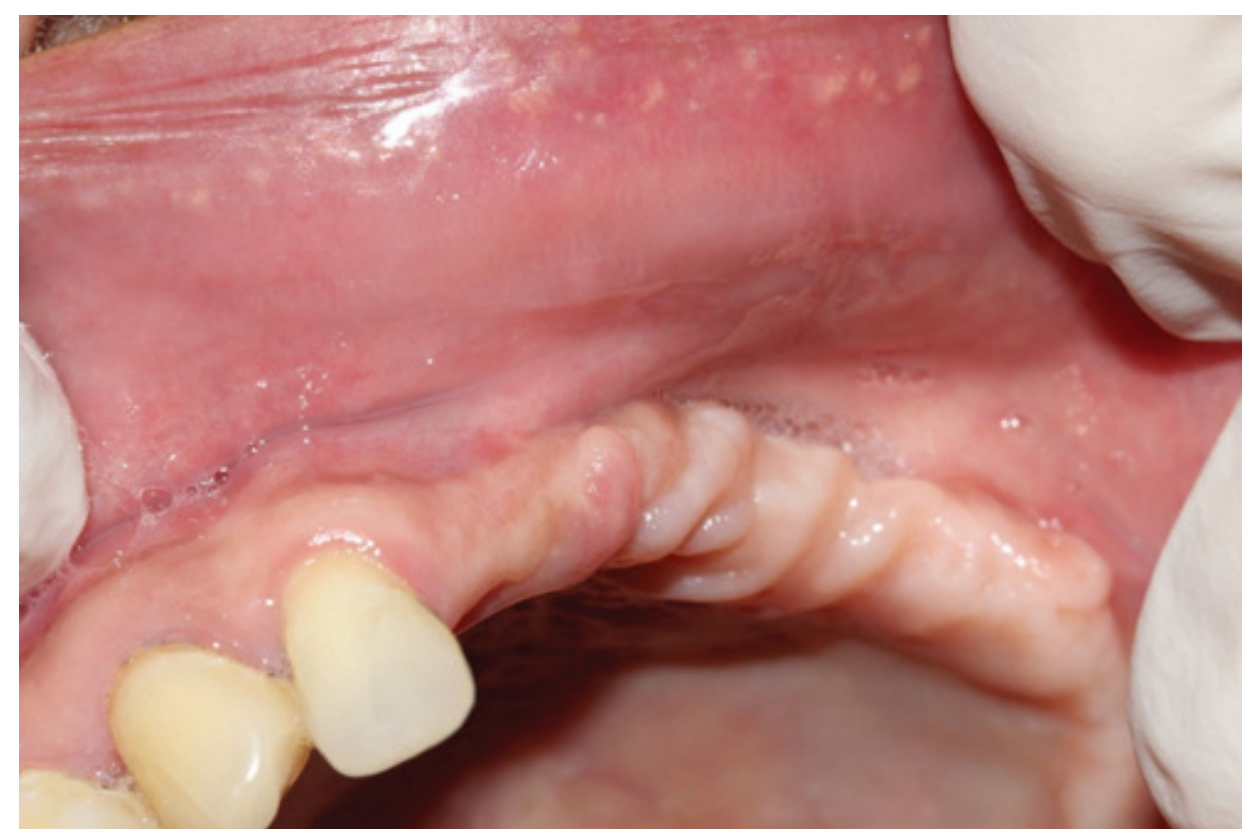

Figura 4 - Controle após 12 meses do procedimento cirúrgico evidenciando ausência de sinais clínicos de recidiva. 


\section{Dıscussão}

O COG é uma lesão rara, representando apenas $0,2 \%$ a $0,8 \%$ de todos os cistos odontogênicos, ${ }^{5,13,14}$ que compartilha algumas das suas características microscópicas com outras lesões císticas e neoplásicas. ${ }^{8,15} \mathrm{~A}$ etiologia do COG, que tem sua histogênese relacionada aos remanescentes da lâmina dentária, permanece desconhecida. ${ }^{15,16} \mathrm{~A}$ mandíbula é afetada em $70 \%$ a $80 \%$ dos casos, dos quais cerca de $55,9 \%$ ocorrem em região anterior. Essa região também é a mais frequente $(88,9 \%)$ para os COGs localizados em maxila. $8,15,17$

Os COGs têm demonstrado uma distribuição ampla em relação à faixa etária, com casos diagnosticados em indivíduos com idades desde os 11 aos 90 anos (média de 45,2 a 51 anos) ${ }^{6-8,17} \mathrm{~A}$ maioria dos estudos relata uma discreta predileção pelo sexo masculino, com relação masculino/feminino variando de 1,1:1 a 1,7:1.8,12,15 Usualmente, os COGs se apresentam como lesões assintomáticas, de crescimento lento, que podem alcançar grandes dimensões e ocasionar, como no caso ora relatado, assimetria facial. ${ }^{6,7,18}$ Esta, associada à mobilidade dentária, foi a principal causa que motivou a paciente a procurar o atendimento odontológico, uma vez que, similarmente ao que é descrito na literatura, a lesão era assintomática.

Radiograficamente, o COG se apresenta como uma área radiolúcida, bem definida, uni ou multilocular, ${ }^{8,12}$ assemelhando-se a outras lesões odontogênicas mais comuns, como o ceratocisto odontogênico e o ameloblastoma. ${ }^{19-21} \mathrm{O}$ último foi a hipótese diagnóstica estabelecida inicialmente para o presente caso. Em $53,8 \%$ a $65,8 \%$ dos casos, - COG revela aspecto unilocular, geralmente com expansão de corticais ósseas vestibular e lingual. $., 12,17$ Suas dimensões podem variar de 0,5 a $12 \mathrm{~cm}$ (média de $4,9 \mathrm{~cm}$ ), com tendência à multilocularidade nas lesões maiores..$^{15}$ Perfuração da cortical óssea pode ser observada em até $61 \%$ dos casos. ${ }^{15,17}$ Por sua vez, associação com dente não erupcionado e reabsorção radicular de dentes adjacentes à lesão ocorrem em $11 \%$ a $31 \%$ e $14 \%$ a $30 \%$ dos casos, respectivamente. ${ }^{12,17}$

Em relação aos achados histopatológicos, os COGs compartilham características com outras lesões císticas e neoplásicas, como o cisto dentígero, o cisto odontogênico botrioide, - cisto cirúrgico ciliado e o carcinoma mucoepidermoide intraósseo de baixo grau. 8,15 Neste contexto, foram desenvolvidos estudos com o intuito de identificar critérios microscópicos que possibilitariam o diagnóstico do COG com segurança, com destaque para os realizados por Fowler et al. ${ }^{8}$ e Kaplan et al. ${ }^{15}$ Os últimos propuseram cinco critérios maiores e quatro critérios menores para o diagnóstico do COG. De acordo com esses autores, todos os critérios maiores (1 - epitélio pavimentoso com interface plana e sem camada basal em paliçada; 2 - variações na espessura do revestimento epitelial [com ou sem enovelados ou proliferações focais luminais]; 3 - células eosinofílicas cuboidais; 4 - células mucosas associadas a coleções intraepiteliais de mucina; e 5 - microcistos ou estruturas semelhantes a ductos) devem estar presentes, mesmo que focalmente, para o diagnóstico do COG. Por sua vez, os critérios menores (1 - proliferações papilares; 2 - células ciliadas; 3 - arquitetura multicística; e 4 - células claras ou vacuoladas) suportam, mas não são necessários para o diagnóstico final do COG. ${ }^{15}$

Aos critérios já descritos, Fowler et al. ${ }^{8}$ adicionaram a metaplasia apócrina das células luminais e sugeriram que é necessária a presença de pelo menos 7 desses 10 critérios para o diagnóstico seguro do COG. Os autores verificaram que a presença de múltiplos espaços císticos $(p=0,006)$, microcistos 
( $p<0,0001)$, células claras $(p=0,0002)$ e enovelados epiteliais $(p<0,0001)$, além da espessura variável do revestimento epitelial ( $p=0,0002)$, são características que podem auxiliar a diferenciar o COG de outras lesões que o mimetizam e todas essas características foram observadas no caso ora descrito. Fowler et al. $^{8}$ constataram, ainda, que em casos associados a coroas de dentes não irrompidos, a presença de microcistos $(p=0,001)$, células claras $(p=0,032)$ e enovelados epiteliais $(p$ $=0,042$ ) pode auxiliar a distinguir o COG do cisto dentígero com alterações metaplásicas. O caso relatado apresentou todos os critérios maiores e três dos critérios menores descritos por Fowler et al. ${ }^{8}$ e Kaplan et al. confirmando o diagnóstico de COG.

Um importante diagnóstico diferencial do COG é o carcinoma mucoepidermoide intraósseo de baixo grau, ${ }^{8}$ especialmente ao serem analisados espécimes provenientes de biópsia incisional. ${ }^{16}$ Embora essas lesões compartilhem características histopatológicas, ao contrário dos carcinomas mucoepidermoides, pesquisas revelam que os COGs são consistentemente negativos para rearranjos no gene MAML2. ${ }^{16,22}$ Apesar disso, o recente estudo realizado por Greer et al. ${ }^{23}$ identificou rearranjos no gene MAML2 em 1 de 11 COGs biologicamente agressivos. Para esses autores, tais achados suportam a teoria de que alguns carcinomas mucoepidermoides intraósseos podem se originar a partir de COGs. ${ }^{23}$

O tratamento do COG inclui desde abordagens cirúrgicas mais conservadoras, como enucleação, marsupialização e curetagem, por vezes com terapias adjuvantes (solução de Carnoy e crioterapia), até abordagens mais agressivas, como a ressecção marginal. A escolha do tratamento depende do estado do paciente, local de envolvimento e tamanho da lesão. ${ }^{10,21}$
Pesquisas evidenciam altas taxas de recorrência para o COG, as quais geralmente se apresentam no período de seis meses a oito anos após o tratamento inicial. 8,12,15 Múltiplas recorrências também têm sido relatadas em alguns casos. ${ }^{8,15}$ Estudos sugerem que COGs de grandes dimensões, com aspecto radiográfico multilocular ou submetidos a tratamento cirúrgico mais conservador, têm maiores propensões à recorrência. ${ }^{11,15}$ Contudo, uma recente revisão de 169 casos de COG descritos na literatura revelou ausência de influências significativas dos aspectos clínicos, radiográficos e do tipo de tratamento na recidiva dessas lesões. ${ }^{17}$

No caso relatado, optou-se pela clivagem óssea perilesional, seguida de curetagem e osteoplastia. Embora não tenham sido identificados sinais de recidiva após um ano de seguimento do caso, considerando a possibilidade de recorrência dos COGs mesmo após oito anos do tratamento inicial, ${ }^{8}$ destacase a necessidade de acompanhamento da paciente em longo prazo.

\section{Considerações finais}

O COG é uma lesão localmente agressiva, cujo diagnóstico diferencial inclui cistos e neoplasias dos ossos gnáticos, com comportamentos biológicos diversos. No caso descrito, as características clínicas e radiográficas sugeriam lesões odontogênicas mais comuns. Assim, a observação dos critérios histopatológicos descritos por Fowler et al. e Kaplan et al. foi essencial para estabelecer o diagnóstico final de COG e excluir outras lesões que o mimetizam. O tratamento proposto se mostrou efetivo no primeiro ano, porém levando-se em consideração a possibilidade de recorrência tardia dos COGs, o acompanhamento da paciente em longo prazo é necessário. 


\section{REFERÊNCIAS}

1. Padayachee A., Van Wyk CW. Two cystic lesions with features of both the botryoid odontogenic cyst and the central mucoepidermoid tumour: sialo-odontogenic cyst? J Oral Pathol 1987; 16 (10): 499-504. https://onlinelibrary.wiley.com/ doi/10.1111/j.1600-0714.1987.tb00680.x

2. Gardner DG, Kessler HP, Morency R., Shaffner DL. The glandular odontogenic cyst: an apparent entity. J Oral Pathol 1988; 17 (8): 359366. https://doi.org/10.1111/j.1600-0714.1988. tb01298.x

3. Kramer IRH, Pindborg JJ, Shear M. Histological typing of odontogenic tumours. WHO international histological classification of tumors, 2nd ed. Tokyo: Springer; 1992, p. 38.

4. El-Naggar AK, Chan JKC, Grandis JR, Takata T., Slootweg PJ. WHO classification of head and neck tumours. WHO/IARC Classification of Tumours, 4th Ed. Lyon: IARC Press; 2017.

5. Sharifian MJ, Khalili M. Odontogenic cysts: a retrospective study of 1227 cases in an Iranian population from 1987 to 2007. J Oral Sci 2011; 53 (3): 361-367. https://doi.org/10.2334/ josnusd.53.361

6. Mascitti M., Santarelli A., Sabatucci A., Procaccini M., Muzio LL, Zizzi A., et al. Glandular odontogenic cyst: review of literature and report of a new case with cytokeratin-19 expression. Open Dent J 2014; 8: 1-12. https:// doi.org/10.2174/1874210601408010001

7. Faisal M., Ahmad SA, Ansari U. Glandular odontogenic cyst-Literature review and report of a paediatric case. J Oral Biol Craniofac Res 2015; 5 (3): 219-225. https://doi.org/10.1016/j. jobcr.2015.06.011

8. Fowler CB, Brannon RB, Kessler HP, Castle JT, Kahn MA. Glandular odontogenic cyst: analysis of 46 cases with special emphasis on microscopic criteria for diagnosis. Head Neck Pathol 2011; 5 (4): 364-375. https://doi. org/10.1007/s12105-011-0298-3

9. Krishnamurthy A., Sherlin HJ, Ramalingam K., Natesan A., Premkumar P., Ramani P, et al. Glandular odontogenic cyst: report of two cases and review of literature. Head Neck Pathol
2009; 3 (2): 153-158. https://doi.org/10.1007/ s12105-009-0117-2

10. Roochi MM, Tavakoli I., Ghazi FM, Tavakoli A. Case series and review of glandular odontogenic cyst with emphasis on treatment modalities. $\mathbf{J}$ Craniomaxillofac Surg 2015; 43 (6): 746-750. https://doi.org/10.1016/j.jcms.2015.03.030

11. Kaplan I., Gal G., Anavi Y., Manor R., Calderon S. Glandular odontogenic cyst: treatment and recurrence. J Oral Maxillofac Surg 2005; 63 (4): 435-441. https://doi.org/10.1016/j. joms.2004.08.007

12. Macdonald-Jankowski DS. Glandular odontogenic cyst: systematic review. Dentomaxillofac Radiol 2010; 39 (3): 127139. https://doi.org/10.1259/dmfr/30943934

13. De Souza LB, Gordón-Núñez MA, Nonaka CF, De Medeiros MC, Torres TF, Emiliano GBG. Odontogenic cysts: demographic profile in a Brazilian population over a 38-year period. Med Oral Patol Oral Cir Bucal 2010; 15 (4): e 58390. https://doi.org/ 10.4317/medoral.15.e583

14. Del Corso G., Righi A., Bombardi M., Rossi B., Dallera V., Pelliccioni GA, et al. Jaw cysts diagnosed in an Italian population over a 20-year period. Int J Surg Pathol 2014; 22 (8): 699-706. https://doi.org/10.1177/1066896914541000

15. Kaplan I., Anavi Y., Hirshberg A. Glandular odontogenic cyst: a challenge in diagnosis and treatment. Oral Dis 2008; 14 (7):575-581. https:// doi.org/10.1111/j.1601-0825.2007.01428.x

16. Speight P., Fowler CB, Kessler H. Glandular odontogenic cyst. WHO classification of head and neck tumours. WHO/IARC Classification of Tumours, 4th Ed. Lyon: IARC Press; 2017, p. 238-239.

17. Chrcanovic BR, Gomez RS. Glandular odontogenic cyst: an updated analysis of 169 cases reported in the literature. Oral Dis 2018; 24 (5): 717-724. https://doi.org/10.1111/ odi.12719

18. Chandra S., Reddy ESP, Sah K., Srivastava A. Maxillary glandular odontogenic cyst: An uncommon entity in an unusual site. Arch Iran Med 2016; 19 (3): 221-224. https://doi. org/0161903/AIM.0012

19. Boffano P., Cassarino E., Zavattero E., Campisi P., Garzino-Demo P. Surgical treatment of 
glandular odontogenic cysts. J Craniofac Surg 2010; 21 (3): 776-780. https://doi.org/10.1097/ SCS.0b013e3181d7a3e6

20. Guruprasad Y., Chauhan DS. Glandular odontogenic cyst of maxilla. J Clin Imaging Sci 2011; 1 (3): 1-3. https://doi. org/10.4103/2156-7514.90074

21. Morais HHA, Vasconcellos RJH, Santos TS, Queiroz LMG, Silveira EJD. Glandular odontogenic cyst: case report and review of diagnostic criteria. J Craniomaxillofac Surg 2012; 40 (2): 46-50. https://doi.org/10.1016/j. jobcr.2015.06.011

22. Bishop JA, Yonescu R., Batista D., Warnock, GR, Westra WH. Glandular odontogenic cysts (GOCs) lack MAML2 rearrangements: a finding to discredit the putative nature of GOC as a precursor to central mucoepidermoid carcinoma. Head Neck Pathol 2014; 8 (3): 287-290. https://doi.org/10.1007/s12105-0140534-8
23. Greer RO, Eskendri J., Freedman P., Ahmadian M., Murakami-Walter A., Varella-Garcia M. Assessment of biologically aggressive, recurrent glandular odontogenic cysts for mastermind-like 2 (MAML2) rearrangements: histopathologic and fluorescent in situ hybridization (FISH) findings in 11 cases. J Oral Pathol Med 2018; 47 (2): 192-197. https://doi. org/10.1111/jop.12658

\section{Autora Responsável:}

Pollianna Muniz Alves

Universidade Estadual da Paraíba - Departamento de Odontologia - Rua Baraúnas, 351 - Bairro Universitário - Campina Grande - PB - Brasil CEP 58429-500 - E-mail: pmunizalves@gmail. com Fone/fax: +55 83 3315-3471

Submetido em: 10-6-2019

Aceito em: 25-7-2019 